\title{
Research on Designing Intentions of Suzhou Style Chair in Ming Dynasty
}

\author{
Weishi Zheng \\ Academy of Fine Arts \\ South China Normal University \\ Guangzhou, Guangdong, China 510631
}

\begin{abstract}
Suzhou style furniture in Ming dynasty has smooth lines, reasonable usage of material in structure and elegant and graceful modeling. It obeys simple and plain design aesthetics and conforms to the peculiarity of scholars pursuing spiritual freedom. As to Suzhou style chair, round-backed armchair, rose chair, ancient folding chair and so on are the most typical modeling images of Suzhou style. They are also representation of the unique literati temperament in Ming dynasty. This paper summarizes from material, decorative material, shape and structure and cultural connotation of Suzhou type chair, analyzes difference between Suzhou type chairs in Ming dynasty and Qing dynasty, and enumerates foreign designed chairs under the influence of Suzhou style furniture in Ming dynasty. Through understanding peculiar cultural spirit contained in Suzhou style furniture of specific areas in specific periods, we can learn Chinese traditional culture and make modern furniture inherit and carry forward craftsmanship and cultural connotation of ancient furniture in an even better way.
\end{abstract}

Keywords - Ming dynasty; Suzhou style furniture; Suzhou style chair; literati temperament; craftsmanship; cultural connotation

\section{INTRODUCTION}

From liangzhu culture in later period of the Neolithic Age to right now, Suzhou is one of the most ancient cities in China with prosperous economy, rich products and beautiful scenery. Suzhou style furniture refers to furniture produced in the lower reaches of Yangtze River with Suzhou as the center. In early Ming dynasty, economy of Suzhou, Hangzhou, Changzhou, Zhenjiang and some other cities rockets. Suzhou style furniture is the representative of Ming style furniture from middle Ming dynasty to early Qing dynasty. Peak of scholars appear in Suzhou in Ming dynasty. They "have outstanding talent and romantic conversation" and blend their pursued spiritual culture in material culture. Ancient Shen further puts forward the so-called "Chairs and couches have reasonable sizes, implements and supplies have proper styles, their location is fixed, and they are unique in being delicate, convenient, simple, smart and not rigid" principle and it gradually becomes a public policy. Wholesale construction of Suzhou garden in Ming dynasty promotes prosperous development of Suzhou furniture manufacturing industry.

\section{TeXTURE AND DECorative Material OF SUZHOU STYLE CHAIR}

\section{A. Texture}

Suzhou style furniture in Ming dynasty mainly uses rosewood, nagkassar, Xichi wood, padauk, annatto, beech, nanmu and so on as its material. For example, yellow pear in Hainan is also called "dalbergia odorifera". According to standard in Redwood, it is defined as scented rosewood. Its wood color is cinnamon and red brown. Its air-dry density is 0.82 to $0.94 \mathrm{~g}$ per cubic centimeters. It has high hardness and smooth section and it is suitable for making throne, official hat chair, table, desk and other classic furniture. It is rarely used in middle Qing dynasty, from which we can know wood is deficient at that time. New flower pear is frequently used in Qing dynasty, which is thicker than yellow pear wood. Its texture is dull without changes and pleasing fragrance. In Fang Yizhi's Tongya of Ming dynasty: "Red sandalwood is rosewood. All red sandalwood comes from south of the five ridges, which means it is imported. Guangdong, Guangxi and Xixidong also produce it." Padauk is also called "red sanders". In Meng Haoran's Liang Zhou Ci: "Completely formed rosewood gold scrap can be made into pipa with resonant sound soaring to the sky". It means that there is padauk in Tang dynasty. Its air-dry density is more than $1.0 \mathrm{~g}$ per cubic centimeters with fine structure. It is suitable for making framed bed, official hat chair, desk, antique-and-curio shelves and other classical furniture. Padauk grows extremely slowly and it can not become useful lumber in less than a hundred years. Therefore, there is the saying of "Most padauk is hollow". Since padauk is very rare and precious in Ming and Qing dynasties, in Map Textural Research on China's Padauk Furniture, Gustave Ecke mentions "Ancient rosewood in products of Qianlong period is also defined as a subspecies of Pterocapus indicus. With waxing and long time maturity, its black red texture is more beautiful, making it possible for this kind of wood to be popular as substitute good of precious padauk. Xichi wood in Ming dynasty has fine and close texture. Deep and shallow purple brown alternates with each other to form patterns, euphemistic and circuitous like floating clouds and flowing water. It is careful in using materials and everything is made relative small. In late Ming and early Qing dynasties, bubinga, rosewood and ebony are used to make 
furniture in great quantity and loved by refined scholars. Nagkassar, walnut, boxwood and gall wood are widely used.

\section{B. Decorative Material}

Suzhou style furniture pursues naturalness and plainness. Most large utensils adopt bezel setting technique, use weed tree as framework, and stick hard thin board on the outside to make furniture. Suzhou carpenters repeatedly observe and measure each block of wood before making furniture to display beautiful part of wood pattern on the surface as decoration as far as possible. As to inlay technique, they also fully use material to calculate carefully and budget strictly. There are mainly six kinds of inlay technique, namely hair carving, flat carving, relief, circular engravure, openwork carving and comprehensive carving. As to decorative material of Suzhou style furniture, there is animal pattern, plant pattern and auspicious patter, such as dragon pattern, phoenix pattern, bat pattern, chi pattern, bamboo pattern, plum pattern, lotus pattern, peony pattern, lucid ganoderma pattern, honeysuckle pattern, cloud pattern and fretted pattern and so on, among which twisted branch is particularly common.

\section{SHAPE AND STRUCTURE AND CULTURAL CONNOTATION OF SUZHOU STYLE CHAIR}

Mr. Wang Shixiang divides shapes of Ming style chair into four types: back-rest chair, armchair, round-backed armchair and ancient folding chair. Ming style chairs use plain wood without painting. They have simple and smooth modeling and accurate tenon and mortise structure, and provide a good curve. They conform to ergonomics. For example, S-shaped backboard, brain beam, handrail, federation stick and so on satisfy people's need of furniture psychologically and physiologically. Mortise and tenon joint used in Ming dynasty mainly includes T-shaped structure, straighter timber corner joint structure, panel and box fitted sheet structure, leg, face and dental plate structure, arc material, supporting part and leg foot structure, and retractable structures of live tenon. The craftsmen achieve mastery of waist furniture and non-waist furniture, creating a new breakthrough in modeling art.

\section{A. Shape and Structure}

1) Backrest chair: Back-rest chair refers to a chair with backrest and without armrest. Backrest consists of a "brain beam", two vertical timbers on both sides and backboard in center. There are two kinds: non-prominent head of both ends and prominent head of both ends. The first type can also be called "single back chair", whose back is similar to backrest of south official hat. Its brain beam's both ends are not prominent and its image is like upright stone tablet. Just as its name implies, dining chair's both ends of brain beam are prominent and its modeling is like bamboo hanging lamp used for supporting oil lamp. Its shape and structure are changeable and diverse. There is square edged timber and round edged timber. It is only used for partial decoration. Dining chair can be seen in Han Xi Banquet Figure. It is usually used in the hall and study. It is also the most common chair type in Ming dynasty.

2) Armchair: The difference between armchair and backrest chair is that armchair has both back and handrail. It has great varieties. Both ends of handrail and top brain beam of backrest are prominent, and they are called "four prominent armchair". Craftsmen in Beijing also call it "official hat chair". It is sometimes called "Chan chair" in Jiangnan area. On the contrary, if a chair's both ends of handrail and brain beam are not prominent, it is called "four non-prominent armchair". It is rarely seen in north. It is called "south official hat chair" in north and "Wen chair" in southern folk. Rose chair is a kind of common Suzhou style armchairs. It is light and portable with low backrest and armrest. There is little difference between height of backrest and armrest. Brain beam and armrest are parallel with seat surface. Rose chair appears in early age. Clauses of "rose chair" can be found in Classics of Lu Ban. It is usually made of rosewood or door frame with exquisite shape, simple and elegant.

3) Folding chair: Ancient folding chair is called "Hu bed" in ancient times. In Ming and Qing dynasties, people call round-backed armchairs with backrest folding chairs and nonround-backed armchairs "Jiao wu" and "folding stool". There is a saying of "the first folding chair". Folding chair symbolizes identity and status of nobility. There are two types: round back and straight back. Round back folding chair is the basic shape and structure while straight back folding chair is a little like deck chair. Relief is used on upper side of back chair plate to open the light and there is "goose doorpost" on both sides. Seat surface is mostly made of hemp rope or leather. The front and back legs cross each other with their joint point as the axis. Foot rest is placed under the bottom of forefoot. Usually, carved broker is set between armrests, backrests and legs and feet. What's more, tenon is usually packaged and inlaid with metal leaves to reinforce and beautify it.

4) Round-backed armchair: Round-backed armchair is also called sieve chair. It appears later than folding chair and is evolved from folding chair. The chair back is round as a circle. It is made of three or five sections of wedge nail tenons and usually appears $\mathrm{S}$ shape or $\mathrm{C}$ shape. Its armrest is prominent. There are securities opposite sides to hold the mouth under seat pan. Legs and feet are round outside and square inside. It is the basic form of round-backed armchair. When people sit on the chair, their both arms go down with the back and armrest, feeling comfortable. In Stink Chapter of Gui er ji written by Zhang Duanyi in Song dynasty: "Today's folding chair is ancient $\mathrm{Hu}$ bed. Carry out ideas to make forty lotus leaf holders, therefore it is called senior great tutor sample". At that time, old-fashioned wooden armchair is a kind of roundbacked armchair with lotus leaf holder. During the development of various kinds of furniture in the world, roundbacked armchair design only exists in Chinese furniture and it is unique. And it conforms to modern ergonomics' requirements for design at the same time. Many foreign designs get inspiration from it to create different modern chairs.

\section{B. Cultural Connotation}

Confucius once said "combining ideal with morality, according to virtue, in accordance with benevolence and sojourn in the arts". Scholars of Ming dynasty contact closely with craftsmen. In fact, it is "sojourn in the arts". They put their humanistic feelings on implements and walk in craft. The biggest function of Suzhou style furniture is practicability. It 
emphasizes high conjunction of beauty and practicability. There are few parts without any function. Scholars of Ming dynasty pursue indifferent life thoughts and interest and uniqueness of craft. Xu Wei's "If reading it can you a sudden start like cold water pouring back, it is an object for imagination, observation, being gregarious and hatred" is exactly the expression of his natural and unrestrained feeling. In Treatise on Superfluous Things: "Boast woods and ravines, appraise wine and tea, and collect location plan history, cups and clangs. They are sundries to other people while they are valuable things to me. The man who offers products observes charm, talent and affection here." It is exactly under this kind of trend of thought that Suzhou style furniture in Ming dynasty has many new patterns.

\section{DIFFERENCE BETWEen SUZHOU STYLE CHAIR OF Ming AND QING DYNASTIES}

In Ming dynasty, there is little red sandalwood. It is expensive and usually owned by imperial nobility. In addition, a large quantity of red sandalwood is imported from foreign countries as fresh live wood. The wood is moist and it needs a period of time to dry before being used to make furniture. Therefore, there is little red sandalwood furniture in reserve. In Ming Style Furniture Appreciation Salvation written by Wang Shixiang, most of the furniture is made of yellow pear wood. In Qing dynasty, there is abundant red sandalwood material in the court and red sandalwood furniture is far more than that in Ming dynasty. Emperor Qianlong is also keen on furniture design.

In early Qing dynasty, Ming style hard wood furniture is produced in many places. Seeing from Suzhou style furniture, we can find that Suzhou's cultural connotation, style features and technology have the most background. Since Suzhou style furniture's manufacturing is relative conservative, it can no longer satisfy Qing dominance hierarchy's need. Therefore, it is gradually replaced by furniture of new styles. For example, European rococo style patterns appear on furniture of Qing dynasty which is mainly used by imperial nobility.

Practical functions are added to Suzhou style furniture in Qing dynasty. Armrest and back curve of chairs develop from euphemistic to hale and hearty. Four-prominent armchair has many aberrant forms of traditional shape and structure. For example, square-edged material obviously occupies an important status, some parts and constructions gradually become stylized; Wen chair's backrest part mainly adopts straight back and high back gradually becomes short; Rose chair and round-backed armchair also display change and creativity of design in handrail, brain beam and back. Suzhou style furniture of Ming dynasty is simple and plain with smooth lines, less carving and inlay and thick literator temperament. Suzhou style furniture of Qing dynasty is wealthy and complicated with delicate carving. Inlay material mainly includes jade, raden, ivory and so on. Since Guangzhou is China's important port for overseas trade, there is abundant wood. Furniture of large size is easy to use, catering for upper class's like of pursuing luxuriousness and gorgeousness. Thus, it replaces the place of Suzhou style furniture quickly.

\section{INFLUENCE OF MING FURNITURE ON FOREIGNERS}

GustavEcké publishes Chinese Padauk Furniture Map Textual Research in 1944, in which 122 pieces of furniture of Ming and Qing dynasties are recorded. It researches Ming and Qing furniture in a true sense and introduces China's classical furniture to various countries in the world at the same time. Robert Hatfield Ellsworth has been researching on Ming style furniture for a long time and he writes the book of Chinese Furniture: Examples of Ming and Qing Hard Wood Furniture in 1970. Due to his collection of Ming furniture known far and wide, he is called "King of Ming dynasty". He once collects a set of 17th century's yellow pear round-backed armchairs, the deal of which is closed at 9685 thousand dollars on 2015 Christie Spring Asia Week in New York in the evening of March 7, 2015. The price is far higher than assessment and creates a new world record of yellow pear furniture auction. Belgian Philippe De Backer has an alias of "Lv Mingshi", which means "living in Ming". The name comes from Wang Shixiang and it is also the largest private collection venue of Ming furniture outside China at present. Danish Hans Vargas is the most deeply influenced designer by China's Ming furniture. The "Chinese" chair designed by him derives from design of China's Ming style furniture -- round-backed armchair. Round-backed armchair develops from folding chair. When sitting down, people's elbow and arm are supported. Thus, it is very comfortable. Ming furniture also reflects eternal modernity and is praised highly by people all over the world.

\section{CONCLUSION}

Many refined scholars of Ming dynasty participate in design research on furniture modeling. They emphasize on practical functions with accurate and precise manufacturing, plain and elegant modeling, reasonable and generous structure, and proper size proportion. The nature cognition that man is an integral part of nature pushes manufacturing craft of Suzhou style furniture to its peak. Although Suzhou style chairs have various kinds of modeling, they always surround a basic point -- simplicity. Only a few lines can create the artistic aesthetic feeling of intangible nature. Mortise and tenon joint organically combines various parts to make Suzhou style chairs on speaking terms with structural features of various parts of human body. It is also the element source for modern designers to draw inspiration.

\section{REFERENCES}

[1] Pu Anguo. Ming and Qing Suzhou Style Furniture[M]. Beijing: The Imperial Palace Press, 2015,4:30.

[2] [Germany]Gustaf Eyck. Chinese Padauk Furniture Map Textual Research[M]. Beijing: Beijing Earthquake Press, 1991.

[3] Wang Yong. Research on Influence of Wu Area Scholars on Ming Furniture[D]. Nanjing Normal University, 2013:32.

[4] Wang Shixiang. Ming Furniture Research[M]. Beijing: Life - Reading - New knowledge Sanlian Bookstore, 2013,7:44.

[5] Zhao Linhong. Ming and Qing Suzhou Style Traditional Chair Research[D]. Northeast Forestry University, 2012:21.

[6] Wu Jia'en. Twenty Years' Recording of Ming Furniture[M]. Beijing: The Imperial Palace Press, 2010,8:91. 
[7] Zhang Duanyi. Gui Er Ji Stink Chapter[M]. Shanghai: Shanghai Ancient Books, 2012,8.

[8] Wen Zhenheng. Superfluous Things[M]. Zhonghua Book Company, 2012,7.

[9] Pu Anguo. Ming and Qing Suzhou Style Furniture[M]. Beijing: The Imperial Palace Press, 2015,4:52-53.

[10] The Fine Arts. "Foreign" Ming Furniture Romance[J]. China Today, 2015,4:94. 